\title{
A simulation and simple optimization of a wind- solar-hydro micro power source with a battery bank as an energy storage device
}

\author{
Jakub Jurasz ${ }^{1, *}$, Adam Piasecki ${ }^{1}$ \\ ${ }^{1}$ AGH University of Science and Technology, Faculty of Management, Cracow, Poland
}

\begin{abstract}
Renewable energy sources (RES) are not the backbone of the Polish electricity generation sector. Even though the use of such resources is beneficial in terms of, e.g., $\mathrm{CO}_{2}$ emissions, current policy seems to create more and more obstacles hindering their further development on an industrial scale. The present paper proposes a simulation model of a hybrid micro power source coupled with a battery bank supplying a small group of households with an annual energy demand of $30 \mathrm{MWh}$. Results indicate that, for the selected site, a power source consisting of a wind turbine $-8 \mathrm{~kW}$, photovoltaic array $-9 \mathrm{~kW}$, water turbine $-2 \mathrm{~kW}$ and $256 \mathrm{kWh}$ energy storage capacity of a battery bank can be a reliable energy source. However, due to the intermittent nature of the selected energy sources there is still a need to remain on-grid in order to avoid excessive energy surpluses (in the case of an oversized system) and deficits. This work opens several interesting directions for future studies, which will be discussed in later sections.
\end{abstract}

\section{Introduction}

Some RESs such as solar, wind and hydro exhibit significant temporal and/or spatial variability [1]. Therefore, a significant amount of research has been conducted in order to quantify, describe and overcome those impediments resulting from the stochastic nature of wind speed, irradiation and flow rate [2,3]. One of the most frequently cited - and questioned [4] - works of Delucchi \& Jacobson [5, 6] points to several solutions which may ease and facilitate the process of integrating variable renewable energy (VRE) into the national power system. Their proposed solutions include, inter alia: the creation of hybrid power sources based on complementary RESs; usage of energy storage devices such as battery banks or hydro-pumped storage, etc.. Research has so far concentrated mainly on the combinations of: PV-battery bank [7], PV-wind turbine-battery bank [8, 9], PV-diesel generator [10] and various, numerous others. In this paper we build upon those concepts and on the research conducted to date on hybrid power sources [11]. In the following section we introduce our vision of a power source consisting of water and wind turbines, an array of photovoltaic modules and a battery bank. The third section describes the mathematical model which will be further used to simulate the behaviour of the proposed power source and enable a simple

\footnotetext{
* Corresponding author: jakubkamiljurasz@,gmail.com
} 
optimization. The second-to-last section describes the obtained results and presents some observations. The conducted research is then summarized in the last section, entitled Conclusions.

\section{RES hybrid energy sources}

The driving force behind the increasing popularity of micro hybrid RES energy sources is the need to overcome the weaknesses of one source (e.g. the diurnal nature of irradiation) with the strengths of another (e.g. the relatively stable energy output from a water turbine). The variable energy output from PV, wind turbine (WT) and, to a lesser degree, from water turbine must meet an energy demand which itself fluctuates (see charts included in Fig. 1). It has been already mentioned that solar, wind and hydro energy to some extent exhibit temporal and spatial complementarity $[12,13,14]$. Therefore, it has been assumed that this is a good premise for investigating the concept of a hybrid RES energy source consisting of the above-indicated energy sources. Furthermore, it is important to note that energy demand can be divided basically into two parts: the so-called 'base load', which remains at much the same level over the course of the year; and local morning and late afternoon demand peaks resulting from residents' behaviour patterns (e.g. preparing meals after work). Hence, it seems reasonable to use a relatively stable energy source in the form of hydropower, which will cover the bulk of baseload demand. Meanwhile, optimally-sized and more variable energy sources (namely PV and WT) coupled with a battery bank will cover the remaining demand.
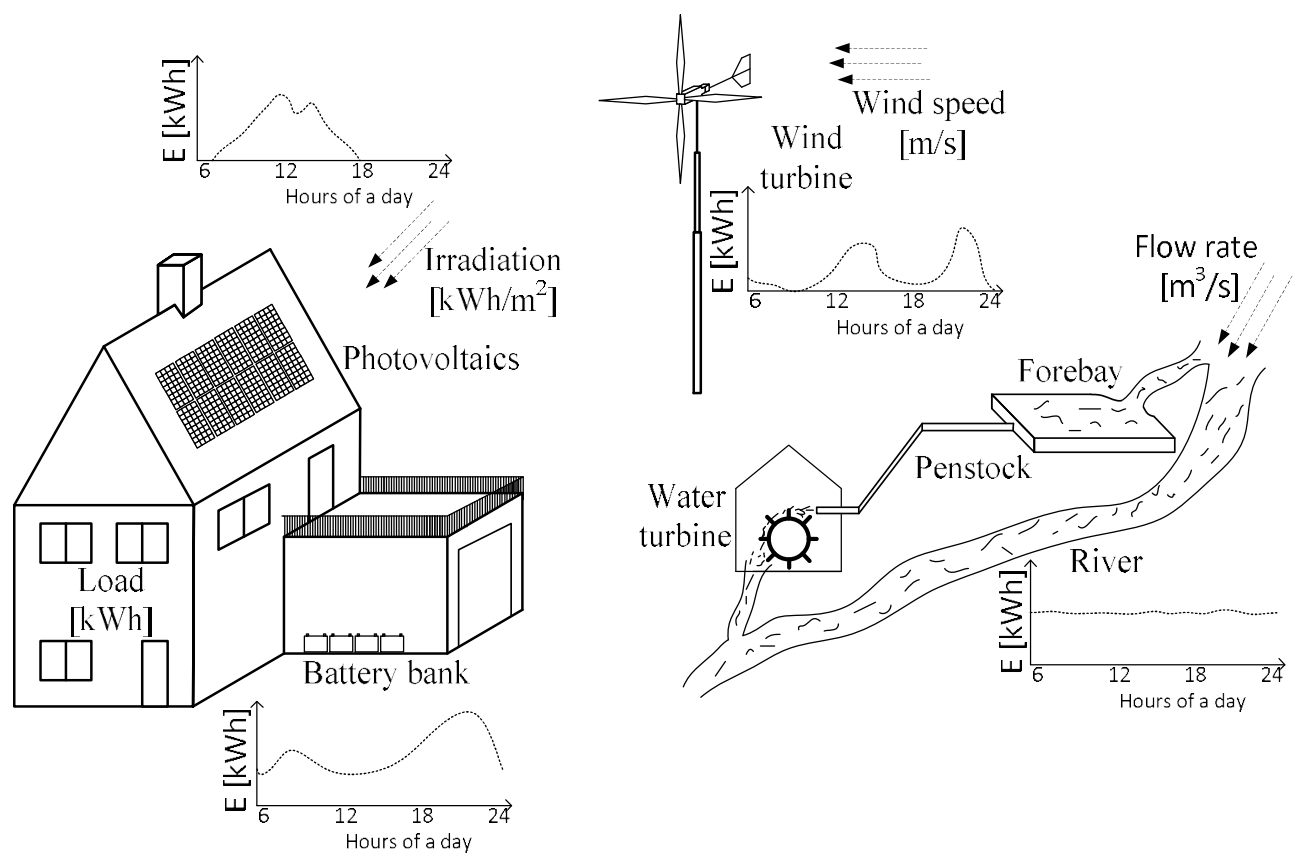

Fig. 1. Conceptual design of an off-grid PV-WT-Hydro hybrid power source. Charts show exemplary energy consumption/yield patterns. 


\section{Simulation model}

After Karkula [15] simulation models are usually applied when it is impossible or very hard to obtain an analytical solution to the investigated problem - such situations occur in the case of dynamic systems. Without simulation it is very hard to predict the impact of individual variables on a system's behaviour. Therefore, by applying various simulation tools (e.g. mathematical models) it is possible to conduct various experiments on a system, to test different scenarios, or, in other words, to change the reality in which the simulated system will operate. In this paper we introduce a binary mathematical model which enables the simulation of a micro power source consisting of a wind turbine and a water turbine, a photovoltaic system and a battery bank. It has been assumed that such a system should be able to cover the energy demand of several households. Theoretically, such a system can be coupled to the power grid in order to ensure that occasional energy surpluses can be transferred via grid to other consumers. Conversely, energy deficits which will inevitably appear in the case of an improperly sized power source can be covered by energy from the power grid. Nonetheless, the impact of VRE energy sources on the power grid should be limited - meaning that unexpected transfer of energy from and to the grid should be as low as absolutely possible. Therefore, in the objective function presented below (see Eq. 12) an assumption has been made to limit the total sum of energy deficits and surpluses. For the sake of simulation model clarity all used variables, coefficients and indices have been summarized in Table 1.

Table 1. Variables, coefficients and indices used in the simulation model

\begin{tabular}{|c|c|c|c|}
\hline \multicolumn{2}{|c|}{ Name } & Variable & Unit \\
\hline \multicolumn{2}{|c|}{ Day/Hour } & $i=1 \ldots 365 / j=1 . .24$ & {$[-]$} \\
\hline \multicolumn{2}{|c|}{ Time interval for calculations } & $t$ & {$[1 \mathrm{~h}]$} \\
\hline \multicolumn{2}{|c|}{ Standard Testing Conditions } & STC & {$\left[\mathrm{kW} / \mathrm{m}^{2}\right]$} \\
\hline \multicolumn{2}{|c|}{ Overall PV installation efficiency } & $\eta^{P V}$ & \multirow[t]{2}{*}[\%]{} \\
\hline \multicolumn{2}{|c|}{ Battery bank charging/discharging efficiency } & $\eta^{\text {cha }} / \eta^{\text {dis }}$ & \\
\hline \multicolumn{2}{|l|}{ Irradiation } & $H_{i j}$ & {$\left[\mathrm{kWh} / \mathrm{m}^{2}\right]$} \\
\hline \multicolumn{2}{|l|}{ Flow-rate } & $Q_{i j}$ & \multirow{3}{*}[\mathrm{m}^{3}/\mathrm{s}]{} \\
\hline \multicolumn{2}{|c|}{ Minimal working flow-rate } & $Q^{\min }$ & \\
\hline \multicolumn{2}{|c|}{ Maximal working flow-rate } & $Q^{\max }$ & \\
\hline \multicolumn{2}{|c|}{ Total head of the hydro turbines used } & $h$ & {$[\mathrm{~m}]$} \\
\hline \multicolumn{2}{|c|}{ Gravity acceleration } & $g$ & {$\left[\mathrm{~m} / \mathrm{s}^{2}\right]$} \\
\hline \multicolumn{2}{|c|}{ Water density } & $\rho$ & {$\left[\mathrm{kg} / \mathrm{m}^{3}\right]$} \\
\hline \multicolumn{2}{|l|}{ Wind speed } & $v_{i j}$ & \multirow{4}{*}[\mathrm{m}/\mathrm{s}]{} \\
\hline \multicolumn{2}{|c|}{ Cut-in wind speed } & $v^{\text {cut-in }}$ & \\
\hline \multicolumn{2}{|c|}{ Cut-out wind speed } & $v^{\text {cut-out }}$ & \\
\hline \multicolumn{2}{|c|}{ Rated output wind speed } & $v^{\text {rated }}$ & \\
\hline \multicolumn{2}{|c|}{$\mathrm{PV} / \mathrm{WT} /$ water turbine nameplate capacity } & $P^{P V} / P^{W T} / P^{H y d r o}$ & {$[\mathrm{~kW}]$} \\
\hline \multirow{2}{*}{$\begin{array}{l}\text { Polynomial } \\
\text { approximating }\end{array}$} & wind turbine power curve & $f(v)$ & {$[-]$} \\
\hline & water turbine efficiency & $f(Q)$ & {$[-]$} \\
\hline \multicolumn{2}{|c|}{ Energy yield: $\mathrm{PV}, \mathrm{WT}$ and water turbine } & $E_{i j}^{P V} / E_{i j}^{W T} / E_{i j}^{H y d r o}$ & \multirow{6}{*}[\mathrm{kWh}]{} \\
\hline \multicolumn{2}{|l|}{ Energy demand } & $E_{i j}^{D}$ & \\
\hline \multicolumn{2}{|c|}{ Energy stored in battery bank } & $E_{i j}^{B B}$ & \\
\hline \multicolumn{2}{|c|}{ Battery bank storage capacity } & $E^{B B_{-} \operatorname{Max}}$ & \\
\hline \multicolumn{2}{|l|}{ Energy surplus } & $E_{i j}^{S}$ & \\
\hline \multicolumn{2}{|l|}{ Energy deficit } & $E_{i j}^{D e f}$ & \\
\hline \multicolumn{2}{|c|}{ Binary variables } & $x_{i j}^{I I . . I I I}$ & {$[0,1]$} \\
\hline
\end{tabular}


For the parameters described in Table 1, the following values have been used in simulation: $S T C=1000 \mathrm{~kW} / \mathrm{m}^{2}, \eta^{P V}=80 \%, \eta^{c h a}$ and $\eta^{\text {dis }}=80 \%, h=1 \mathrm{~m}, g=9.81 \mathrm{~m} / \mathrm{s}^{2}, \rho=1000$ $\mathrm{kg} / \mathrm{m}^{3}$. Irradiation $\left(H_{i j}\right)-($ www.soda-pro.com $)$, wind speed $\left(v_{i j}\right) /$ flow rate $\left(Q_{i j}\right)-$ IMGW NRI (www.imgw.pl), and energy demand $\left(E^{D}\right)-$ [9] time series covered the year 2015 and had a one-hour time step. Those time series were representative for the area near Ostrowiec Świętokrzyski, located in south-central Poland. The polynomial approximating and water turbine efficiency have been calculated based on data presented by Kaldellis [16] for a small Kaplan turbine, and the other, describing the wind turbine power curve, has been calculated for a small, 1-kW, horizontal-axis wind turbine manufactured by Kastrel (www.kestrelwind.co.za). The following subsections introduce formulas and equations used to determine the values of individual variables. Note that in formulas describing energy generation, indices have been omitted.

Energy yield from PV - after [14]

$$
E^{P V}=\frac{H P^{P V}}{S T C} \eta^{P V} t
$$

Energy yield from wind turbine - after [14]

$$
E^{W T}=\left\{\begin{array}{c}
0, \text { for } v<v^{\text {cut }- \text { in }} \\
f(v) t, \text { for } v^{\text {cut }- \text { in }} \leq v<v^{\text {rated }} \\
P^{W T} t, \text { for } v^{\text {rated }} \leq v \leq v^{\text {cut }- \text { out }}
\end{array}\right.
$$

Energy yield from water turbine - after [16]

$$
\begin{gathered}
E(Q)=f(Q) \rho g h Q t \\
E^{\text {Hydro }}=\left\{\begin{array}{c}
0, \text { for } Q \leq Q^{\text {min }} \\
E(Q), \text { for } Q^{\text {min }} \leq Q \leq Q^{\text {max }} \\
P^{\text {Hydro } t, \text { for } Q^{\text {max }} \leq Q}
\end{array}\right.
\end{gathered}
$$

Energy flow

$$
\begin{gathered}
E_{i j}^{B 1}=E_{i j}^{P V}+E_{i j}^{T W}+E_{i j}^{H y d r o}-E_{i j}^{D} \\
x_{i j}^{I}=\left\{\begin{array}{l}
1, \text { if } E_{i j}^{B 1} \geq 0 \\
0, \text { otherwise }
\end{array}\right.
\end{gathered}
$$

Battery bank - modified after [17]

$$
E_{i, j+1}^{B B}=\min \left[\left(E_{i, j}^{B B}+\eta^{c h a} E_{i j}^{B 1}\right) x_{i j}^{1} ; E^{B B_{M a x}}\right]+\max \left[\left(E_{i, j}^{B B}+\frac{E_{i j}^{B 1}}{\eta^{d i s}}\right)\left(1-x_{i j}^{1}\right) ; 0\right]
$$

Energy deficit

$$
x_{i j}^{I I}=\left\{\begin{array}{l}
1, \text { if } E_{i j}^{B B}=0 \\
0, \text { otherwise }
\end{array}\right.
$$




$$
E_{i j}^{D e f}=\left|E_{i, j-1}^{B B}+\frac{E_{i j}^{B 1}}{\eta^{d i s}}\right| x_{i j}^{I I}
$$

Energy surplus

$$
\begin{gathered}
x_{i j}^{I I I}=\left\{\begin{array}{c}
1, \text { if } E_{i j}^{B B}=E^{B B_{M a x}} \\
0, \text { otherwise }
\end{array}\right. \\
E_{i j}^{S}=\min \left(\left(E_{i j}^{B 1}-\frac{E^{B B_{M a x}}-E_{i j-1}^{B B}}{\eta^{c h a}}\right) x_{i j}^{I I I} ; 0\right)
\end{gathered}
$$

Optimization - objective function

$$
\min Z=\sum_{i=1}^{365} \sum_{j=1}^{24} E_{i j}^{D e f}+\sum_{i=1}^{365} \sum_{j=1}^{24} E_{i j}^{S}
$$

The above-described model assumes that energy flow is possible only between selected components (see Fig. 2). However, the precise values of energy used from, e.g., wind turbines, to cover the energy demand, or how much energy from PV will be stored in the battery bank remained beyond the scope of this study. Therefore, formulas for their calculation will not be presented.

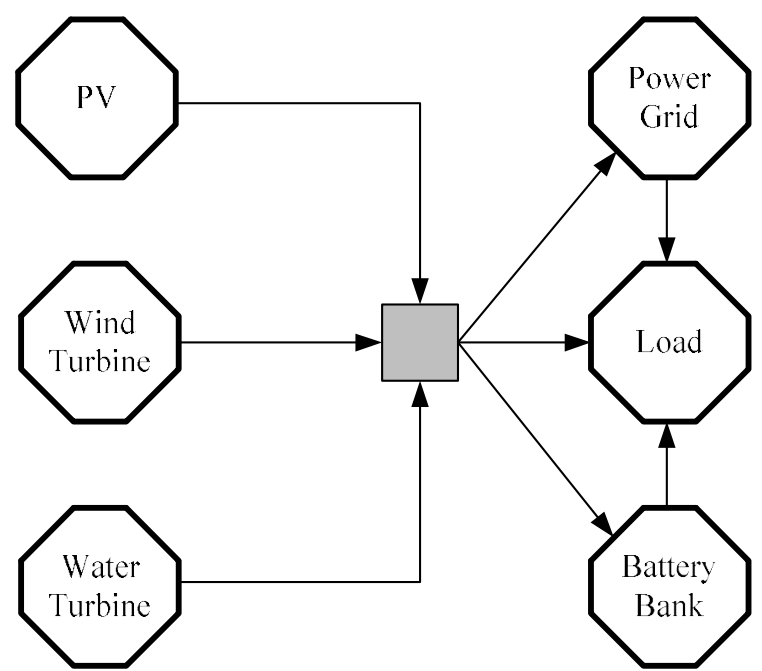

Fig. 2. Energy flow in the investigated hybrid power source which in theory has been connected to the power gird

\section{Results and discussion}

The creation of hybrid RES power sources is mainly based on the assumption that the selected energy sources will complement each other, thereby providing a stable power source. Such systems, in which the failure of one component will not impede $100 \%$ effectiveness, are known as parallel reliability structures [19]. For the purpose of this study a one-year-long hourly time series of wind speed, flow rate and irradiation covering the year 2015 was 
selected. Based on formulas (1, 2, 3 and 4), the energy yield for a photovoltaic array, wind and water turbine (each rated $2 \mathrm{~kW}$ ) have been calculated. Fig. 3 depicts the energy output from hydropower as a function of energy yield from photovoltaics and wind turbine. The nominal capacity of the water turbine for the given flow time series has been estimated based on [18]. As can be observed, in the case that there is no energy generation from PV one can statistically expect a significant amount of energy from hydropower, but only when there is also energy available from wind turbines (above 30\% of WT rated capacity). On the other hand, when there is plenty of energy from PV and moderate energy yield from WT, the observed energy generation from hydropower will be relatively low (below $75 \%$ of the rated capacity of the water turbine). Of course the dependencies presented above are valid only for the selected parameters of the water turbine and might change significantly if another were selected. Please note that this chart (Fig. 3) refers to energy generated by devices such as wind turbines etc., not the potential energy availability resulting from wind speed or irradiation.

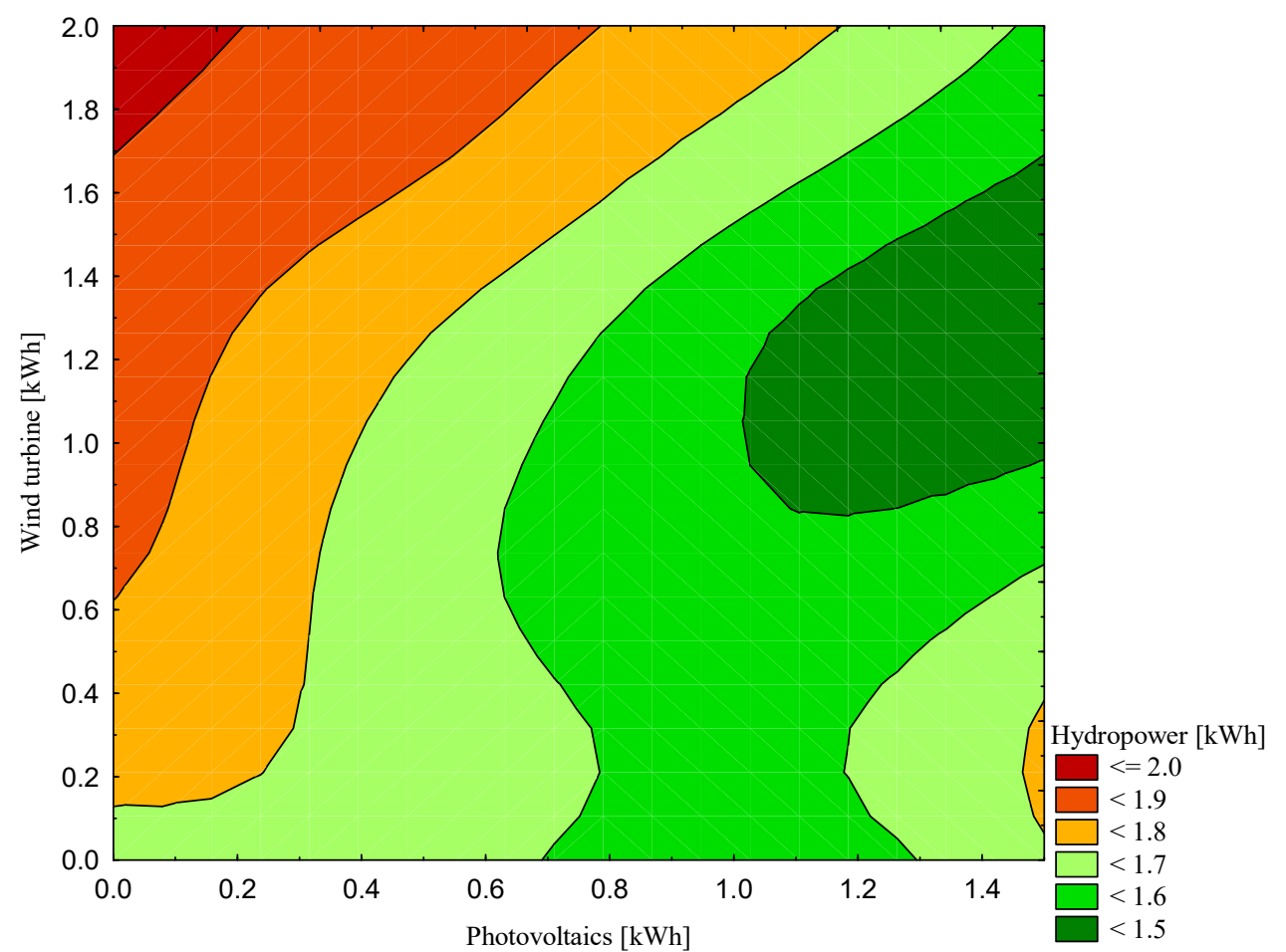

Fig. 3. Energy generation from photovoltaics, wind turbine and water turbine, each rated $2 \mathrm{~kW}$

For the purpose of this study a time series depicting the energy demand of a group of several household has been selected. The total annual energy consumption amounted to $30 \mathrm{MWh}-$ which translates to a mean daily energy demand of $82.2 \mathrm{kWh}$. Based on Eq. 1-11 the behaviour of such an energy source has been simulated. The optimal nameplate capacity of wind turbines, PV arrays and battery bank has be estimated by an Excel Non-Linear solver. Prior to the optimization, the following constraints were imposed: the nameplate capacity of PV, WT and battery bank must be an integer value; additionally, the capacity of the battery bank cannot exceed the average two-day energy consumption plus theoretical energy losses. Therefore, the maximal battery bank capacity should not exceed $256 \mathrm{kWh}$. The results obtained indicate that the optimal value of the objective function will be achieved for the 
following input variable values: $\mathrm{P}^{\mathrm{PV}}=9 \mathrm{~kW}, \mathrm{P}^{\mathrm{WT}}=8 \mathrm{~kW}, \mathrm{E}^{\mathrm{BB}} \_\mathrm{Max}=256 \mathrm{kWh}$. As a result, the proposed system will cover over $92 \%$ of the initial energy demand, whilst energy surpluses will be slightly over $1.8 \mathrm{MWh}$. The energy deficit will be equal to $2.25 \mathrm{MWh}$. This means that by adding a little bit to the energy generating capacity of the proposed hybrid energy source the overall energy balance might be equal to zero. The exemplar energy generation and demand values are presented in Fig. 4. Note the significant energy surpluses from the wind generation and smooth energy generation from water turbine.

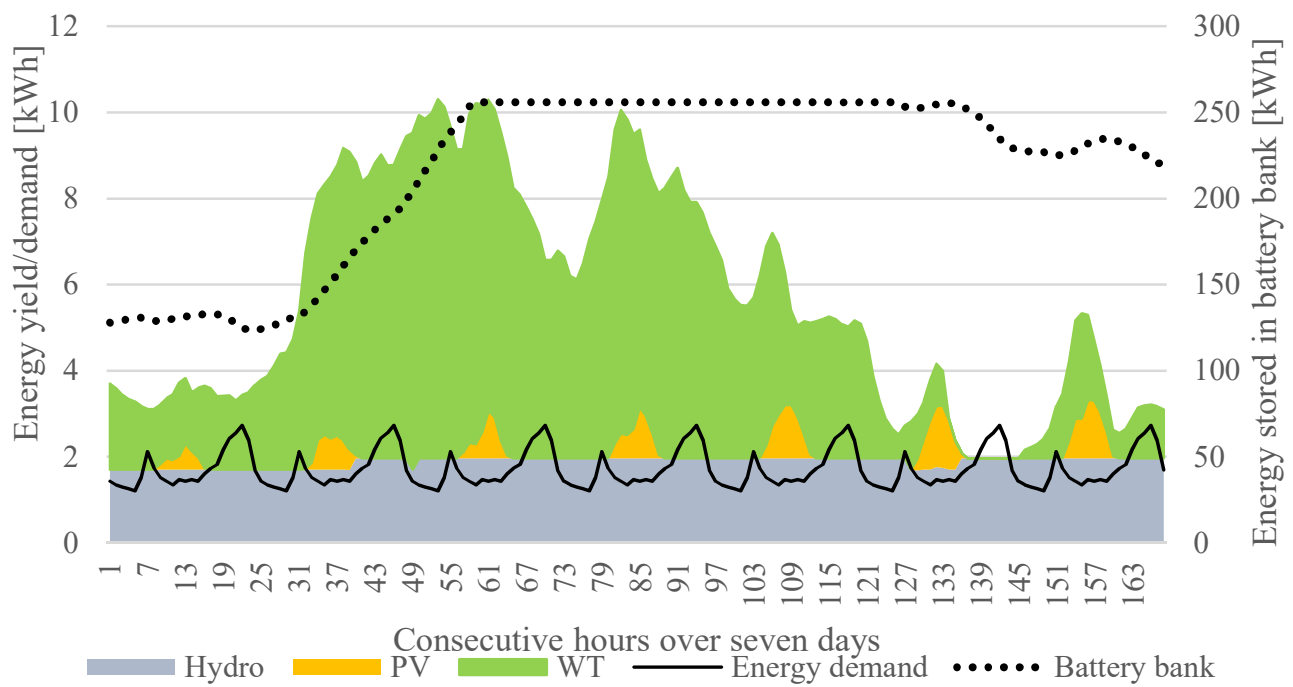

Fig. 4. Energy generation, demand and storage over seven consecutive days in January

The seasonal and diurnal patterns of energy generation and demand make the sizing procedure very complicated. The conducted simulation enabled us to grasp those patterns and estimate the optimal nameplate capacities. In Fig. 5 we have presented the cumulative mean energy generation values for the three investigated energy sources. Please note the impact of the relatively low energy yield values in February and October on the mean hourly volume of energy stored in battery bank, which is depicted in Fig. 6.

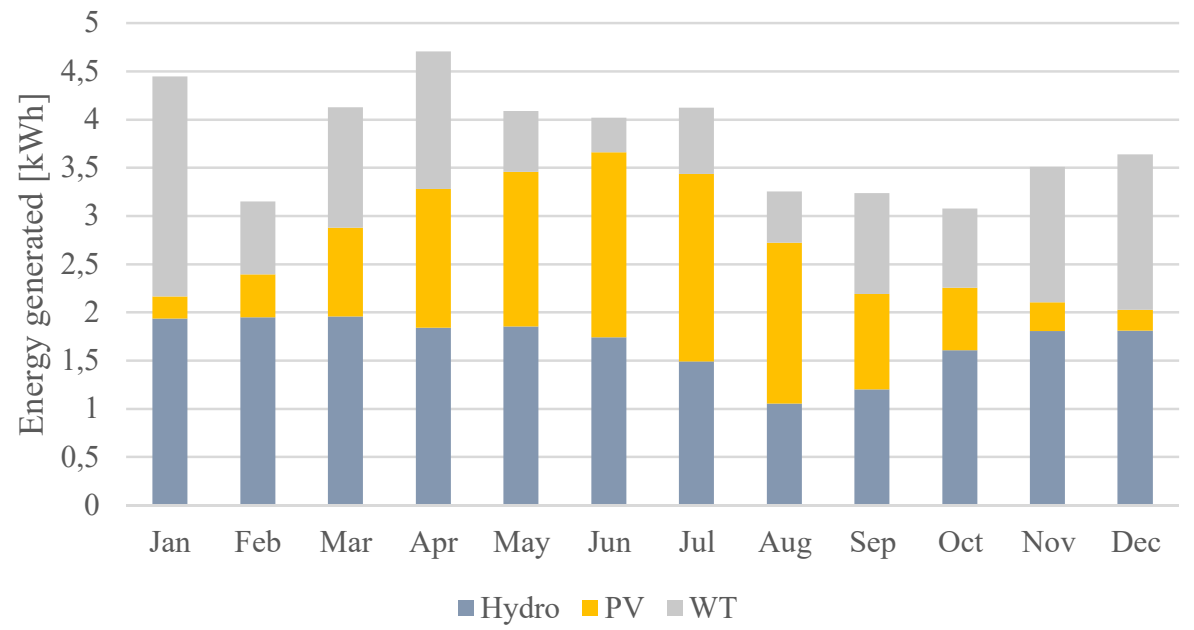

Fig. 5. Mean hourly energy generation from selected sources within individual months 


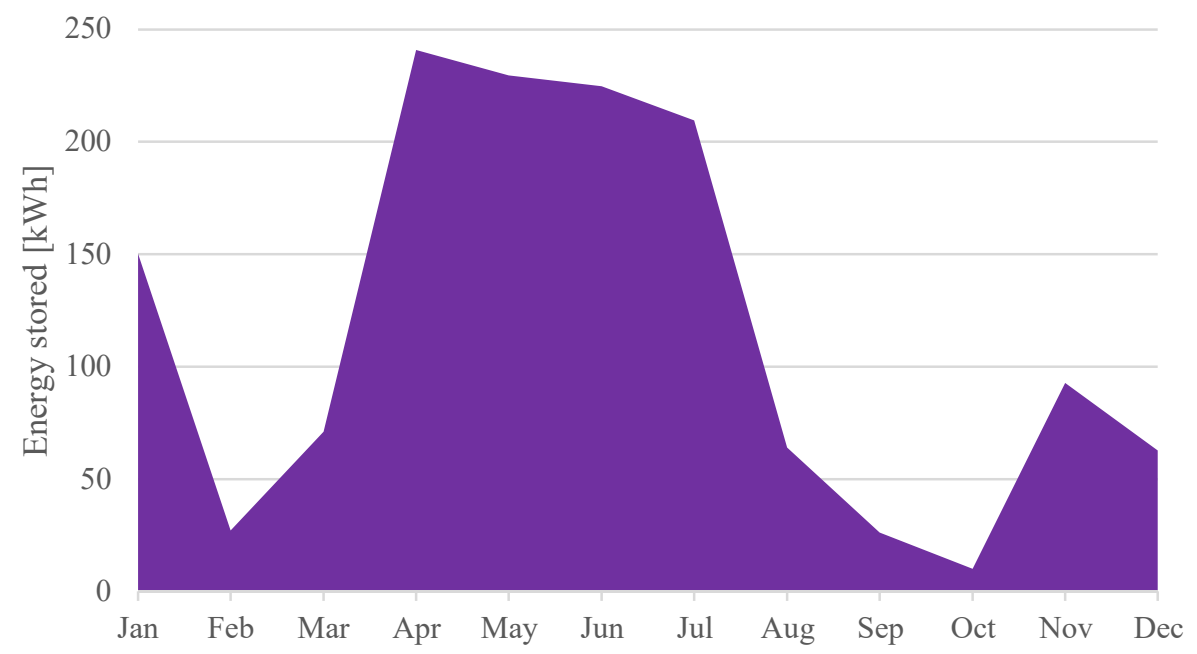

Fig. 6. Mean hourly volume of energy stored in battery bank during each month

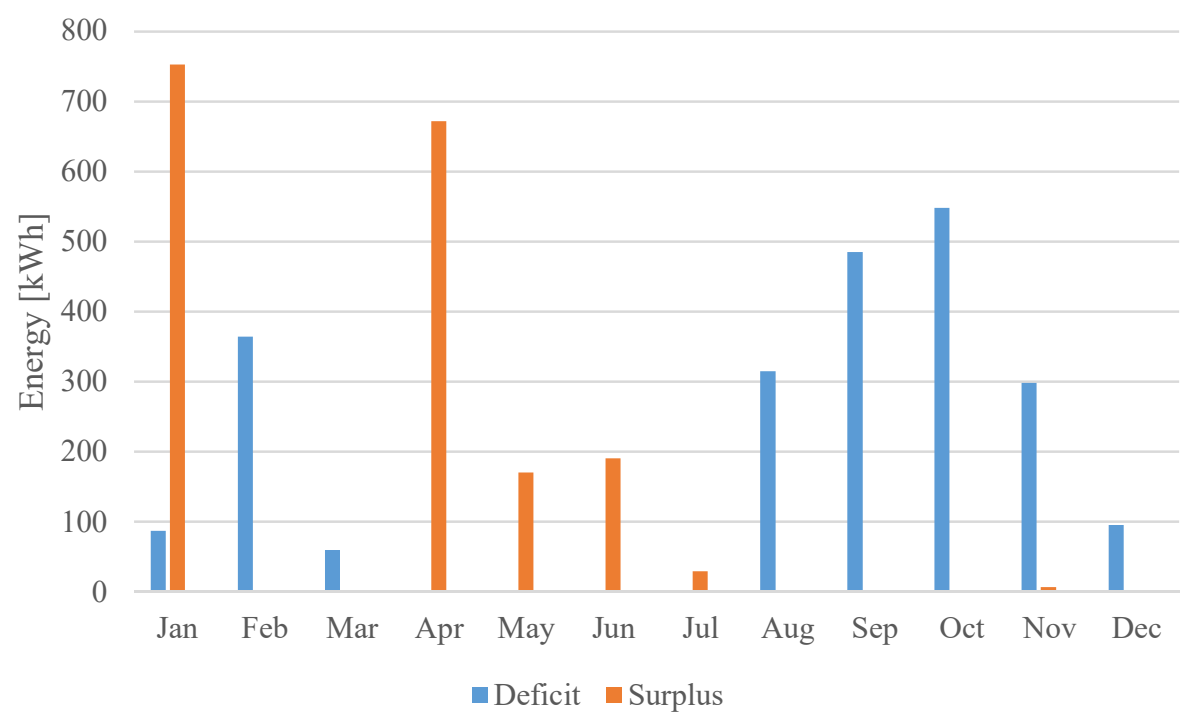

Fig. 7. Sum of energy deficits and surpluses occurring over the course of the investigated year

A decrease in energy availability from PV, WT and hydropower results in increased use of the battery bank and the more frequent occurrence of energy deficits (see Fig. 7). The opposite can be observe in months such as January and April, when the energy generation from wind turbines leads to a significantly higher overall energy generation than in the remaining months. Note that, in those two months alone, the energy surpluses accounted for almost $80 \%$ of the total energy surplus observed over the simulation period. However, the variable nature of wind and irradiation values and the limited capacity of the battery bank lead to a situation where some energy deficit occurred even in January. The question therefore arises of what nameplate capacities for individual components of this hybrid energy source would ensure energy self-sufficiency. To partially investigate this issue we decided to gradually increase the capacity of the battery bank. The obtained results are depicted in Fig. 8. 


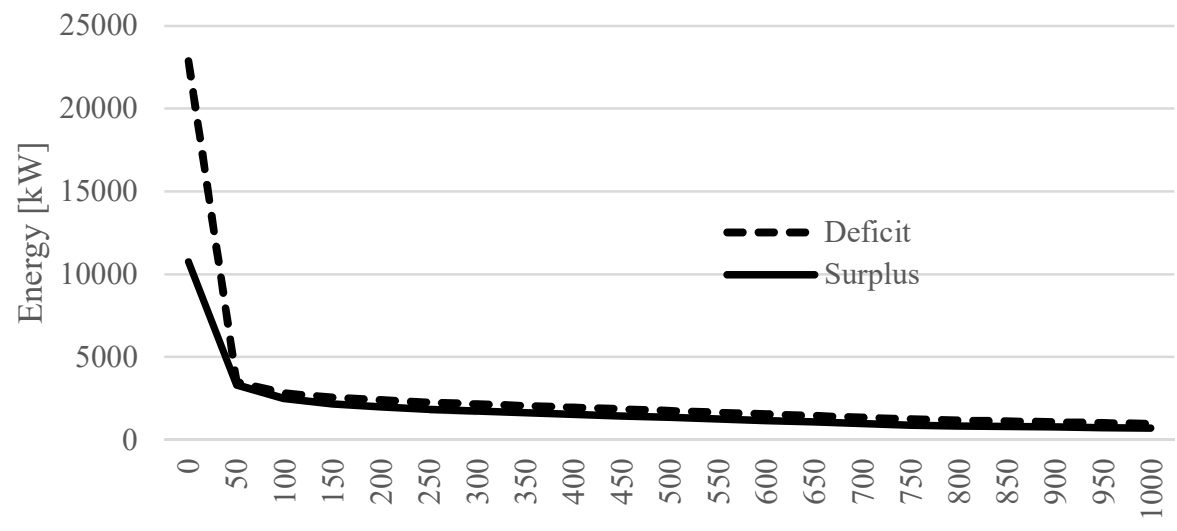

Batery bank capacity [kWh]

Fig. 8. Energy deficit and surplus as a function of battery bank capacity

As can be seen in Fig. 8, the most significant decrease in energy deficit and surplus can be observed for battery capacities ranging from 0 to $50 \mathrm{kWh}$. This highlights the role and importance of energy storage devices when using energy sources which rely on variable renewable energy sources. The data presented in Fig. 8 reveals that, for the selected nameplate capacities of energy sources and patterns of energy demand, each $\mathrm{kWh}$ added to the battery bank capacity (for capacity ranging from 200 to $1000 \mathrm{kWh}$ ) will result in a 1.6 $\mathrm{kWh}$ decrease in energy deficit.

\section{Conclusions}

An analysis of the available literature indicates that hybrid renewable energy power sources are gaining importance due to the increasing role of RESs in power systems. Greater capacity installed in VRE requires actions to enable their smooth and cost-effective integration. One of the viable solutions is to introduce to the power system new RESs which are complementary in time, thereby limiting and curtailing the probability of instances of concurrent zero energy availability from all VREs. Referring back to the current state of knowledge, the majority of models focuses on realizing given objective functions, such as meeting a given energy demand or minimizing total energy generation costs. In this paper we have introduced a simple yet effective mathematical model which enables the simulation of a micro power source which generates electric energy from three variable renewable energy sources. The model has been tested on a potential hybrid power source located in one Polish voivodeship. The single objective optimization function enabled us to determine the nameplate capacity of wind turbines, photovoltaics and battery bank. Due to the volumetric constraints of this paper, several interesting issues have not been raised. These include: estimation of nameplate capacities which will enable energy self-sufficiency; and the impact of adding more capacity to the wind turbines and photovoltaics on energy surpluses and deficits. What is more, the proposed hybrid power source should be juxtaposed with an energy source which uses only wind and solar energy - because it tends to exhibit positive correlation with energy demand over certain periods [20], or only one of those sources. Finally, it is worth underlining that the presented model can easily be enhanced with the economic and environmental aspects of the proposed hybrid energy source, and this will be the scope of our future research. 


\section{References}

1. E. L. Jones, Renewable energy integration: practical management of variability, uncertainty, and flexibility in power grids, Academic Press (2014)

2. J. Kleissl, Solar energy forecasting and resource assessment, Academic Press (2013)

3. C. E. Hoicka, I. H. Rowlands, Solar and wind resource complementarity: Advancing options for renewable electricity integration in Ontario, Canada, Renewable Energy, 26(1), 97-107, (2011)

4. T. Trainer, A critique of Jacobson and Delucchi's proposals for a world renewable energy supply, Energy Policy, 44, 476-481, (2012)

5. M. A. Delucchi, M. Z. Jacobson, Providing all global energy with wind, water, and solar power, Part I: Technologies, energy resources, quantities and areas of infrastructure, and materials, Energy Policy, 39(3), 1154-1169 (2011)

6. M. Z. Jacobson, M. A. Delucchi, Providing all global energy with wind, water, and solar power, Part II: Reliability, system and transmission costs, and policies, Energy policy, 39(3), 1170-1190 (2011)

7. M. Mehrabankhomartash, et al., Practical battery size optimization of a PV system by considering individual customer damage function, Renewable and Sustainable Energy Reviews, 67, 36-50 (2017)

8. S. K. Nandi, H. R. Ghosh, Prospect of wind-PV-battery hybrid power system as an alternative to grid extension in Bangladesh, Energy, 35(7), 3040-3047, (2010)

9. J. Jurasz, J. Mikulik, Solar \& wind hybrid power source for residential building mathematical model approach, Architecture Civil Engineering Environment, 8(4), 5-10 (2015)

10. R. Dufo-López, J. L. Bernal-Agustín, Design and control strategies of PV-Diesel systems using genetic algorithms, Solar energy, 79(1), 33-46 (2015)

11. O. Bajpai, V. Dash, Hybrid renewable energy systems for power generation in standalone applications: a review, Renewable and Sustainable Energy Reviews, 16(5), 29262939 (2012)

12. J. Jurasz, A. Piasecki, Evaluation of the Complementarity of Wind Energy Resources, Solar Radiation and Flowing Water-a Case Study of Piła, Acta Energetica, 2 (2016)

13. F. Monforti, et al., Assessing complementarity of wind and solar resources for energy production in Italy. A Monte Carlo approach, Renewable Energy, 63, 576-586 (2014)

14. S. Jerez, et al., Spatio-temporal complementarity between solar and wind power in the Iberian Peninsula, Energy Procedia, 40, 48-57 (2013)

15. M. Karkula, Weryfikacja i walidacja dynamicznych modeli symulacyjnych procesów logistycznych, Logistyka, 2, 717-726, (2012)

16. J. K. Kaldellis, et al., Techno-economic evaluation of small hydro power plants in Greece: a complete sensitivity analysis, Energy Policy 33(15), 1969-1985 (2005)

17. H. Ren, et al., Optimal operation of a grid-connected hybrid PV/fuel cell/battery energy system for residential applications, Energy, 113, 702-712 (2016)

18. B. Karolewski, P. Ligocki, Wyznaczanie parametrów małej elektrowni wodnej, Praca Naukowe Instytutu Maszyn, Napędów i Pomiarów Elektrycznych Politechniki Wrocławskiej, 56 (2004)

19. B. Tchórzewska-Cieślak, Niezawodność i bezpieczeństwo systemów komunalnych: na przykładzie systemu zaopatrzenia $w$ wode, Oficyna Wydawnicza Politechniki Rzeszowskiej (2008)

20. J. Jurasz, J. Mikulik, Investigating Theoretical PV Energy Generation Patterns with Their Relation to the Power Load Curve in Poland, International Journal of Photoenergy, 7 pages, 2016. doi:10.1155/2016/3789840 (2016) 